\title{
Expression of ghrelin and leptin during the development of type 2 diabetes mellitus in a rat model
}

\author{
SONGYUN ZHANG ${ }^{1}$, QINGJIU ZHANG ${ }^{2}$, LIHUI ZHANG ${ }^{1}$, CEGE LI $^{1}$ and HUIQING JIANG ${ }^{3}$ \\ Departments of ${ }^{1}$ Endocrinology and ${ }^{2}$ Neurosurgery, The Second Hospital of Hebei Medical University; \\ ${ }^{3}$ Department of Gastroenterology, Hebei Key Laboratory of Gastroenterology, Hebei Institute of Gastroenterology, \\ The Second Hospital of Hebei Medical University, Shijiazhuang 050000, P.R. China
}

Received June 23, 2012; Accepted October 15, 2012

DOI: $10.3892 / \mathrm{mmr} .2012 .1154$

\begin{abstract}
The aim of this study was to investigate the systematic changes in ghrelin and leptin expression, as well as their correlation with insulin resistance (IR) during the development of type 2 diabetes mellitus (T2DM) in a rat model. T2DM was induced in rats fed a high-fat (HF)-diet followed by the intraperitoneal injection of low-dose streptozotocin (STZ, $35 \mathrm{mg} / \mathrm{kg}$ ). Sixty male Sprague-Dawley rats were divided into 4 groups: the control, HF-4W (HF diet for 4 weeks), HF-8W (HF diet for 8 weeks) and the T2DM group. During the development of T2DM, the production of ghrelin in the stomach and leptin in adipose tissue, the blood levels of ghrelin and leptin, and the expression of leptin and ghrelin receptors (OB-Rb and GHS-R1a) in the hypothalamus were measured by enzymelinked immunosorbent assay (ELISA), radioimmunology assay (RIA), immunohistochemistry (IHC) and real-time reverse transcription-polymerase chain reaction (real-time RT-PCR). IR was assessed using the hyperinsulinemic-euglycemic clamp technique. The production of ghrelin in the stomach, the plasma ghrelin levels and the expression of GHS-R1a in the hypothalamus were significantly reduced in the HF-4W and HF- $8 \mathrm{~W}$ rats compared with the control rats; however, no significant difference was found between the HF-8W and T2DM group rats. Comparing the control to the T2DM group, the production of leptin in the adipose tissue and the serum leptin levels increased, whereas the expression of OB-Rb in the hypothalamus decreased. At the same time, the glucose infusion rate (GIR), indicating the insulin sensitivity, decreased significantly; GIR positively correlated with plasma ghrelin and negatively correlated with serum leptin levels. In conclusion, increased leptin levels are associated with obesity and T2DM,
\end{abstract}

Correspondence to: Dr Huiqing Jiang, Department of Gastroenterology, Hebei Key Laboratory of Gastroenterology, Hebei Institute of Gastroenterology, The Second Hospital of Hebei Medical University, No. 215 Hepingxi Road Xinhua District, Shijiazhuang 050000, P.R. China

E-mail: huiqingjiang@yahoo.com.cn

Key words: type 2 diabetes mellitus, ghrelin, GHS-Rla, leptin, $\mathrm{OB}-\mathrm{Rb}$ while decreased ghrelin levels are associated with obesity/IR rather than T2DM.

\section{Introduction}

Type 2 diabetes mellitus (T2DM), a rapidly increasing worldwide epidemic (1-3), is a metabolic disease caused by the interaction of genetic and environmental factors. Insulin resistance (IR) and $\beta$-cell dysfunction are the main pathophysiological factors that contribute to the development of T2DM.

Ghrelin, a 28-amino acid peptide predominantly produced by the stomach, is the only known peripherally produced hormone that stimulates food intake and decreases energy expenditure $(4,5)$. Leptin, a 167 -amino acid peptide mainly secreted from white adipocytes, is a key afferent signal that suppresses food intake and increases energy expenditure $(6,7)$. Following release into the circulation, both ghrelin and leptin cross the blood-brain barrier and bind to their receptors in the arcuate nucleus (ARC) of the hypothalamus $(8,9)$. The two hormones play a role in the regulation of energy balance and glucose metabolism (9-11).

The present study was conducted to investigate the changes in the expression of ghrelin and leptin and their correlation with IR in the development of T2DM in the rat, which involves the production of ghrelin and leptin in the stomach and adipose tissue, the blood levels of the two hormones and the expression of their receptors in the ARC of the hypothalamus.

\section{Materials and methods}

Animals. Sixty male Sprague-Dawley rats (6 weeks of age, bred at Hebei Medical University, China) were used for the experiments. All procedures were performed in accordance with the Regulations for the Administration of Affairs Concerning Experimental Animals. The protocol was approved by the Hebei Medical University Animal Care Research Committee. All rats were kept at $23-24^{\circ} \mathrm{C}$ on a $12 / 12$-h light/dark cycle. Animals were randomly divided into 4 groups: i) the control group ( $n=15$, fed standard laboratory chow); ii) the HF-4W group [n=15, fed a high-fat (HF) diet for 4 weeks (HF diet consisting of 5\% fat, $55 \%$ carbohydrates, $22 \%$ protein, $7 \%$ ash and $5 \%$ fiber); iii) the HF-8W group ( $\mathrm{n}=15$, fed a HF diet for 8 weeks); and iv) the T2DM group (12-15) [n=12, after 8 weeks of the HF diet, 15 rats 
were administered a streptozotocin (STZ) injection $(35 \mathrm{mg} / \mathrm{kg}$ ); 10 days later, 12 rats with fasting blood glucose (FBG) above $200 \mathrm{mg} / \mathrm{dl}$ were enrolled in the T2DM group].

The body weight of the rats was monitored once every week. FBG, total cholesterol (TC) and triglycerides (TG) were determined by an automatic biochemistry analyzer (Beckman X20; Beckman Coulter, Miami, FL, USA).

Hyperinsulinemic-euglycemic clamp. After an overnight fast for over $12 \mathrm{~h}$, the rats were anesthetized with pentobarbital sodium (50 mg/kg, intraperitoneally), and the left jugular vein and left femoral artery were catheterized for infusion and blood sampling, respectively. The glucose and insulin solutions were stored in 2 digital syringe pumps and were joined by a ' $\mathrm{Y}$ ' connector to the jugular catheter. Human insulin (Novolin R, Novo Nordisk, Bagsvaerd, Denmark) was continuously infused at $10 \mathrm{mU} / \mathrm{kg} / \mathrm{min}$ for $2 \mathrm{~h}$. The blood glucose concentration was clamped at the basal level by estimating blood glucose concentration at $5 \mathrm{~min}$ intervals in samples taken from the femoral artery and adjusting the rate of infusion of a $20 \%$ glucose solution. Clamping was achieved by $60 \mathrm{~min}$ and was maintained for $60 \mathrm{~min}$. The glucose infusion rate (GIR) during the second hour of the clamp was taken as a response parameter, indicating insulin sensitivity.

Enzyme-linked immunosorbent assay. At 8:00 a.m. after overnight fasting for over $12 \mathrm{~h}$, blood was obtained from the rats and was transferred into chilled tubes with $1 \mathrm{mg} / \mathrm{ml}$ EDTA-2Na and $500 \mathrm{U} / \mathrm{ml}$ aprotinin. Blood samples were immediately centrifuged at $4^{\circ} \mathrm{C}(1,600 \mathrm{rpm}$ for $15 \mathrm{~min})$ and were stored at $-80^{\circ} \mathrm{C}$ until assay. After the rats were sacrificed, the stomach was quickly removed, immediately frozen in liquid nitrogen and stored at $-80^{\circ} \mathrm{C}$. To quantify plasma and stomach ghrelin levels, a commercial ghrelin enzyme-linked immunosorbent assay (ELISA) kit (Phoenix Pharmaceuticals, Inc., Burlingame, CA, USA) was used according to the manufacturer's instructions. Inter- and intra-assay coefficients of variation were $<14$ and $<5 \%$, respectively.

Radioimmunology assay. After overnight fasting for over $12 \mathrm{~h}$, blood was collected in tubes with gel and clot activator and centrifuged at $4^{\circ} \mathrm{C}(1,600 \mathrm{rpm}$ for $15 \mathrm{~min})$ to obtain serum. Blood serum was stored at $-80^{\circ} \mathrm{C}$ until assay. Epididymal fat pads were separated from the left side of each rat during experiments, and they were immediately frozen in liquid nitrogen and stored at $-80^{\circ} \mathrm{C}$. Cold normal saline $(1 \mathrm{ml})$ was added to each $200 \mathrm{mg}$ epididymal fat pad sample; samples were homogenized at $20,000 \mathrm{rpm}$ for $30 \mathrm{sec}$ at $4^{\circ} \mathrm{C}$, repeated twice at an interval of $10 \mathrm{sec}$. The homogenate was centrifuged at $12,000 \mathrm{rpm}$ for $20 \mathrm{~min}$ at $4^{\circ} \mathrm{C}$; the supernatant was collected and stored at $-20^{\circ} \mathrm{C}$. Serum and adipose leptin and serum insulin were determined by radioimmunology assay (RIA) with leptin and insulin RIA kits (Beijing Hi-Tech Atomic Technology, Inc., Beijing, China) according to the manufacturer's instructions.

RNA extraction and real-time reverse transcription-polymerase chain reaction (real-time $R T$-PCR). The stomach, left epididymal fat pad and hypothalamus were rapidly excised, snap-frozen on dry ice and immediately processed for RNA isolation. Total RNA was extracted using TRIzol reagent (Invitrogen, Carlsbad,
CA, USA) according to the manufacturer's instructions. Single-stranded complementary DNA (cDNA) was synthesized using Moloney murine leukemia virus (MMLV) reverse transcriptase with random hexamer primers. Quantitative real-time PCR was performed using SYBR ${ }^{\circledR}$ Premix Ex Taq ${ }^{\mathrm{TM}}$ (Takara, Shiga, Japan) on the ABI PRISM 7000 Sequence Detection System (Applied Biosystems, Carlsbad, CA, USA) according to the manufacturer's instructions. The mRNA level was normalized to the housekeeping gene $\beta$-actin. The fold-change for an mRNA from control to HF (or DM) was calculated as $2^{(-\Delta \Delta C t)}$, where $\Delta \Delta \mathrm{Ct}=\Delta \mathrm{Ct}$ control $-\Delta \mathrm{Ct} \mathrm{HF}$ (or $\Delta \mathrm{Ct} \mathrm{DM}$ ) and $\Delta \mathrm{Ct}=\mathrm{Ct}$ mRNA - CT-actin mRNA. The primers and thermal cycle parameters are shown in Table I.

Immunohistochemistry. Animals were anesthetized and intracardially perfused with 0.1 M PBS followed by freshly prepared $4 \%$ paraformaldehyde in PBS. The stomach and brain were removed, postfixed overnight, paraffin embedded and cut into 5- $\mu \mathrm{M}$ sections with a microtome. After the paraffin had been removed, endogenous peroxidase activity was blocked with $3 \%$ hydrogen peroxide for $10 \mathrm{~min}$ at room temperature (RT). The slides were microwaved for $20 \mathrm{~min}$ in $0.01 \mathrm{M}$ citrate buffer (pH 6.0). Slides were rinsed in PBS and then blocked with $10 \%$ goat serum (Sigma, St. Louis, MO, USA) for $30 \mathrm{~min}$ at RT. Tissue slices were incubated with primary antibodies (1:100) overnight at $4^{\circ} \mathrm{C}$ and were washed with PBS for $5 \mathrm{~min}$ 3 times before a reaction with secondary antibody for $1 \mathrm{~h}$ at RT. The slides were reacted with 3,30-diaminobenzidine tetrahydrochloride (DAB) for 1-3 min at RT for a color reaction, and then they were counterstained with Mayer's hematoxylin and observed under a microscope. Negative controls were reacted with PBS instead of primary antibodies. The primary antibodies used were rabbit anti-mouse ghrelin, rabbit antimouse GHS-R1a (Phoenix Pharmaceuticals, Inc., Burlingame, $\mathrm{CA}, \mathrm{USA}$ ) and rabbit anti-mouse OB-Rb (Beijing Biosynthesis Biotechnology Co., Ltd., Beijing, China). The secondary antibody used was a biotinylated goat anti-rabbit IgG. Image Pro Plus 6.0 software was used for imaging analysis.

Statistical analysis. All data are expressed as the means \pm SEM. A normality and a homogeneity test for variance were conducted. One-way analysis of variance (ANOVA) and Student-Newman-Keuls (SNK) pairwise multiple comparisons were used to assess differences in the means among groups. The Pearson correlation test was performed between 2 parameters. All analyses were performed using SPSS for Windows, version 10.0. $\mathrm{P}<0.01$ was considered to indicate a statistically significant difference.

\section{Results}

Body weight and serum concentrations. Comparing the HF-8W to the control group, the average body weight increased significantly $(\mathrm{P}<0.01)$; however, no significant difference was found between the HF-8W and T2DM groups ( $\mathrm{P}>0.05)$. The TC and TG serum concentrations increased significantly $(\mathrm{P}<0.01)$ in the T2DM compared to the control group. The average FBG levels of the control, HF-4W and HF-8W groups were similar, but in the T2DM group, levels increased to $9.38 \pm 0.56 \mathrm{mmol} / 1$ $(\mathrm{P}<0.01$, Table II). 
Table I. Ghrelin, leptin and their receptors as well as actin primer sequences and PCR thermal cycle parameters.

\begin{tabular}{|c|c|c|}
\hline Target gene & Primer sequence & PCR thermal cycle parameters \\
\hline Ghrelin mRNA (160 bp) & $\begin{array}{l}\text { 5'-CAGAGCACCAGAAAGCCCAGCAG-3' } \\
\text { 5'-CCAACATCGAAGGGAGCATTGAA-3' }\end{array}$ & $\begin{array}{l}95^{\circ} \mathrm{C} 10 \mathrm{~min}, 95^{\circ} \mathrm{C} 5 \mathrm{sec}, 57^{\circ} \mathrm{C} 10 \mathrm{sec}, 72^{\circ} \mathrm{C} 31 \mathrm{sec} \\
(35 \text { cycles }), 72^{\circ} \mathrm{C} \text { extended } 5 \mathrm{~min}\end{array}$ \\
\hline Leptin mRNA (67 bp) & $\begin{array}{l}\text { 5'-GGAAGCCTCGCTCTACTCCA-3' } \\
\text { 5'-GAATGTCCTGCAGAGAGCCC-3' }\end{array}$ & $\begin{array}{l}95^{\circ} \mathrm{C} 10 \mathrm{~min}, 95^{\circ} \mathrm{C} 5 \mathrm{sec}, 58^{\circ} \mathrm{C} 10 \mathrm{sec}, 72^{\circ} \mathrm{C} 31 \mathrm{sec} \\
(40 \text { cycles }), 72^{\circ} \mathrm{C} \text { extended } 5 \mathrm{~min}\end{array}$ \\
\hline GHS-R1a mRNA (246 bp) & $\begin{array}{l}\text { 5'-TTCTGCCTCACTGTGCTCTACAGT-3' } \\
\text { 5'-AGCCAGTACTGCAACCTGGTGTCC-3' }\end{array}$ & $\begin{array}{l}94^{\circ} \mathrm{C} 5 \mathrm{~min}, 94^{\circ} \mathrm{C} 45 \mathrm{sec}, 53^{\circ} \mathrm{C} 40 \mathrm{sec}, 72^{\circ} \mathrm{C} 45 \mathrm{sec} \\
(35 \text { cycles }), 72^{\circ} \mathrm{C} \text { extended } 5 \mathrm{~min}\end{array}$ \\
\hline OB-Rb mRNA (116 bp) & $\begin{array}{l}\text { 5'-GCA GCT ATG GTC TCA CTT CTT TTG-3' } \\
\text { 5'-GGT TCC CTG GGT GCT CTG A-3' }\end{array}$ & $\begin{array}{l}94^{\circ} \mathrm{C} 5 \mathrm{~min}, 94^{\circ} \mathrm{C} 45 \mathrm{sec}, 52^{\circ} \mathrm{C} 40 \mathrm{sec}, 72^{\circ} \mathrm{C} 45 \mathrm{sec} \\
(35 \text { cycles }), 72^{\circ} \mathrm{C} \text { extended } 5 \mathrm{~min}\end{array}$ \\
\hline$\beta$-actin (110 bp) & $\begin{array}{l}\text { 5'-ATCCGTAAAGACCTCTATGCCAACA-3' } \\
\text { 5'-GCTAGGAGCCAGGGCAGTAATCT-3' }\end{array}$ & \\
\hline
\end{tabular}

Table II. The average body weight, TC, TG, FBG, insulin levels and GIR in the control, HF-4W, HF-8W and T2DM groups.

\begin{tabular}{lcccc}
\hline & Control & HF-4W & HF-8W & T2DM \\
\hline Body weight $(\mathrm{g})$ & $237.12 \pm 15.65$ & $356.20 \pm 20.49^{\mathrm{a}}$ & $488.12 \pm 29.17^{\mathrm{a}}$ & $495.41 \pm 34.53^{\mathrm{a}}$ \\
TC (mmol/l) & $1.15 \pm 0.77$ & $2.21 \pm 0.30^{\mathrm{a}}$ & $3.42 \pm 0.35^{\mathrm{a}}$ & $3.83 \pm 0.48^{\mathrm{a}}$ \\
TG (mmol/l) & $0.91 \pm 0.13$ & $1.44 \pm 0.16^{\mathrm{a}}$ & $2.18 \pm 0.23^{\mathrm{a}}$ & $2.92 \pm 0.25^{\mathrm{a}}$ \\
FBG (mmol/l) & $5.34 \pm 0.33$ & $5.40 \pm 0.32$ & $5.60 \pm 0.38$ & $9.38 \pm 0.56^{\mathrm{a}}$ \\
Insulin (IU/ml) & $16.98 \pm 1.75$ & $22.57 \pm 2.01^{\mathrm{a}}$ & $30.48 \pm 2.08^{\mathrm{a}}$ & $27.41 \pm 1.58^{\mathrm{a}, \mathrm{b}}$ \\
GIR (mg/kg/min) & $12.70 \pm 0.54$ & $10.16 \pm 0.49^{\mathrm{a}}$ & $7.72 \pm 0.36^{\mathrm{a}}$ & $6.25 \pm 0.32^{\mathrm{a}, \mathrm{b}}$ \\
\hline
\end{tabular}

${ }^{\mathrm{a}} \mathrm{P}<0.01$ vs. control group, ${ }^{\mathrm{b}} \mathrm{P}<0.01$ vs. HF-8W group. TC, total cholesterol; TG, triglycerides; FBG, fasting blood glucose; GIR, glucose infusion rate.

Circulating insulin and GIR. The serum insulin levels increased from the control to the HF-8W group $(\mathrm{P}<0.01)$; however, compared with the HF-8W group, the levels decreased significantly in the T2DM group $(\mathrm{P}<0.01)$. Compared with the control rats, GIR was gradually reduced in the HF-4W, HF- $8 \mathrm{~W}$ and T2DM group rats $(\mathrm{P}<0.01$, Table II).

Gastric ghrelin. The gastric ghrelin levels were reduced significantly in the HF-4W and HF-8W rats compared with the control rats $(\mathrm{P}<0.01)$, whereas no significant differences were found between the HF-8W and T2DM rats $(\mathrm{P}>0.05 ; 0.81 \pm 0.11$ in the control rats, $0.67 \pm 0.11$ in the $\mathrm{HF}-4 \mathrm{~W}$ rats, $0.57 \pm 0.11$ in the HF- $8 \mathrm{~W}$ rats and $0.59 \pm 0.09$ in the T2DM group rats). The ghrelin mRNA levels and ghrelin-expressing cells showed similar results (Fig. 1A and B).

Circulating concentrations of ghrelin. Compared with the control rats $(2.03 \pm 0.22 \mathrm{ng} / \mathrm{ml})$, the plasma ghrelin level was significantly suppressed in the HF-4W and HF-8W rats $(1.81 \pm 0.20$ and $1.63 \pm 0.11 \mathrm{ng} / \mathrm{ml} ; \mathrm{P}<0.01)$; however, there were no significant differences between the HF-8W and T2DM group rats $(1.64 \pm 0.13 \mathrm{ng} / \mathrm{ml} ; \mathrm{P}>0.05)$.

Expression of GHS-Rla. Compared with the control rats, a significant reduction in the number of GHS-R1a-expressing cells was observed in the ARC from the control to the HF-8W rats $(\mathrm{P}<0.01$, Fig. 2A); however, no significant differences were observed between the HF-8W and T2DM rats $(\mathrm{P}>0.05$, Fig. 2A). Accordingly, total hypothalamic GHS-R1a mRNA showed similar results $(\mathrm{P}<0.01$, Fig. $2 \mathrm{~B})$

Adipose leptin. Compared with the control rats, there were significantly increased adipose leptin levels in the HF-4W, HF-8W and T2DM rats $(\mathrm{P}<0.01$, Fig. $3 \mathrm{~A})$. Accordingly, the leptin mRNA levels in the adipose tissue showed similar results $(\mathrm{P}<0.01$, Fig. 3B $)$.

Circulating concentrations of leptin. During the development of T2DM, the circulating concentrations of leptin gradually, yet significantly increased in the HF-4W, HF-8W and T2DM group rats $(\mathrm{P}<0.01$, Fig. 4$)$.

Expression of $O B-R b$. With the development of T2DM, in the ARC of the hypothalamus, the number of OB-Rb-expressing cells reduced significantly $(\mathrm{P}<0.01$, Fig. 5A). Similarly, total hypothalamic OB-Rb mRNA levels decreased significantly when comparing the control to the T2DM group $(\mathrm{P}<0.01$, Fig. 5B).

Correlation between GIR and plasma ghrelin, and between GIR and serum leptin. Pearson correlation analysis demonstrated a significant negative correlation between the plasma 


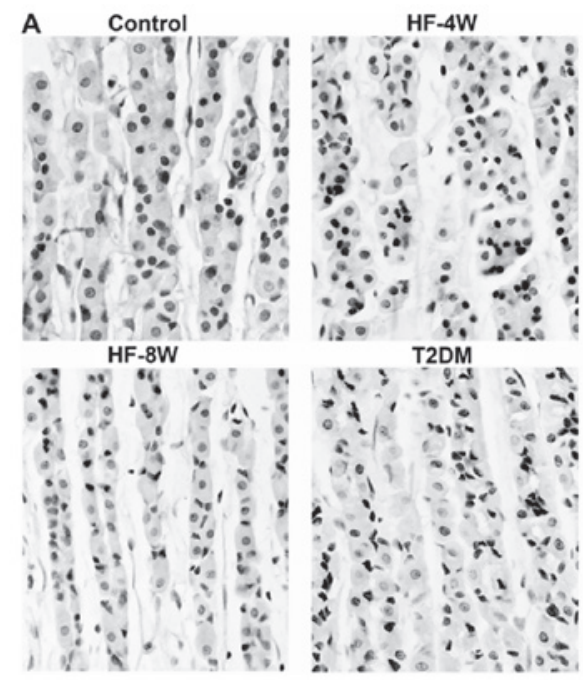

B

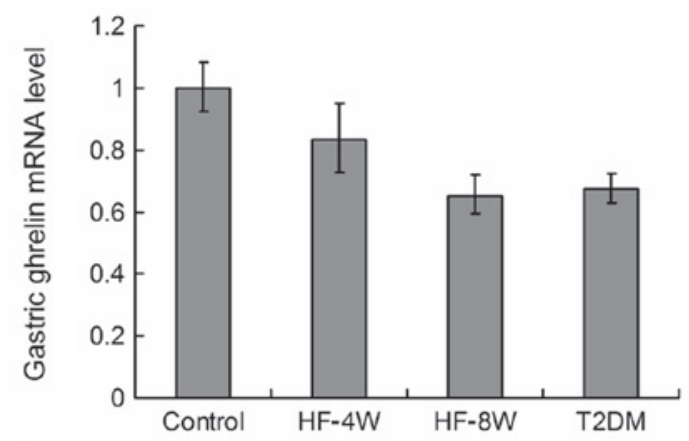

Figure 1. (A) The number of ghrelin-expressing cells in the stomach was reduced when comparing the HF-8W group to the control rats ( $\mathrm{P}<0.01)$, whereas no significant differences were found between the HF-8W and T2DM group rats ( $>0.05)$. Magnification, $\mathrm{x} 400$. (B) The expression of ghrelin mRNA revealed similar results. T2DM, type 2 diabetes mellitus.

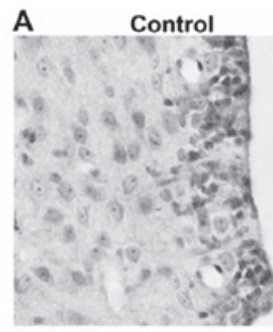

HF-8W

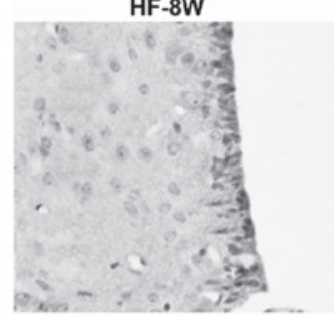

HF-4W

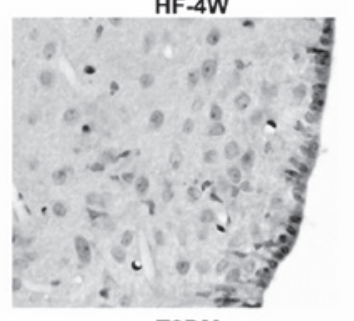

T2DM

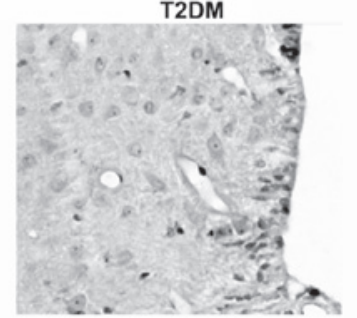

B

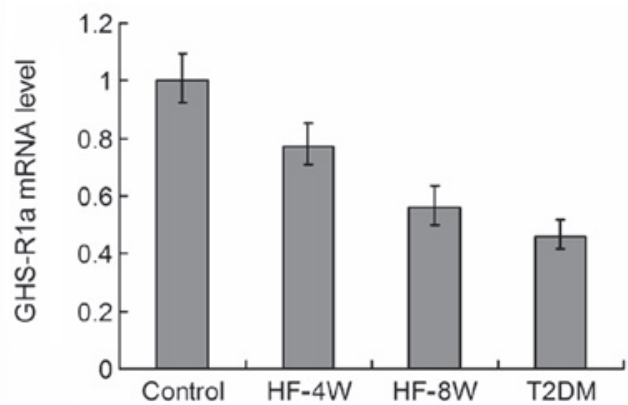

Figure 2. (A) The number of GHS-R1a-expressing cells in ARC was reduced when comparing the HF-8W group to the control rats ( $\mathrm{P}<0.01$ ), whereas no significant differences were found between the HF-8W and T2DM group rats $(\mathrm{P}>0.05)$. Magnification, $\mathrm{x} 400$. (B) The expression of GHS-R1a mRNA showed similar results. ARC, arcuate nucleus; T2DM, type 2 diabetes mellitus.
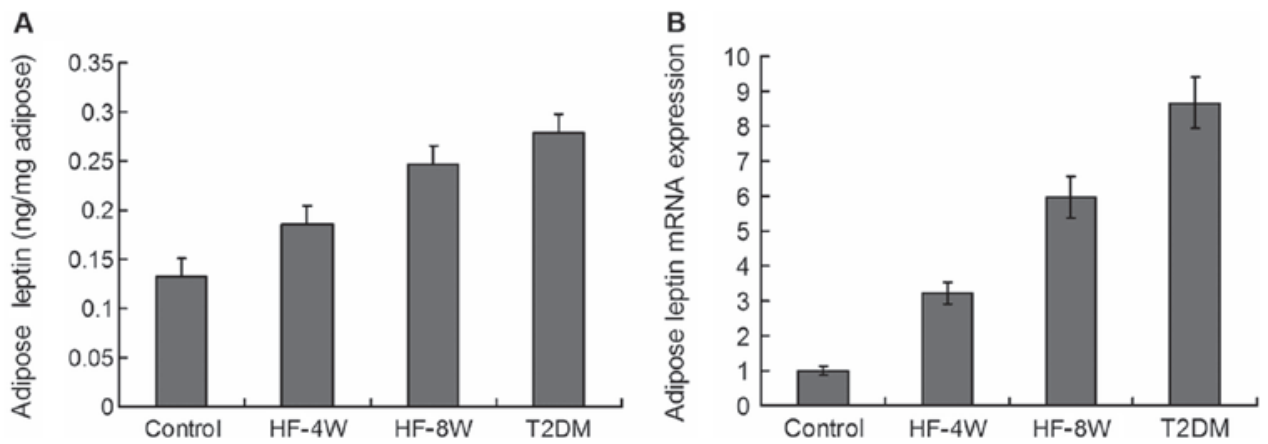

Figure 3. (A) The adipose leptin levels and (B) the expression of leptin mRNA in the adipose tissue increased significantly when comparing the T2DM group to the control rats $(\mathrm{P}<0.01)$. T2DM, type 2 diabetes mellitus.

ghrelin and serum leptin levels $\left(\mathrm{r}=-0.813, \mathrm{r}^{2}=0.551, \mathrm{P}=0.001\right)$. GIR positively correlated with plasma ghrelin levels $(\mathrm{r}=0.945$, $\left.\mathrm{r}^{2}=0.893, \mathrm{P}=0.0001\right)$ and negatively correlated with serum leptin levels $\left(\mathrm{r}=-0.973, \mathrm{r}^{2}=0.946, \mathrm{P}=0.001\right)$. 


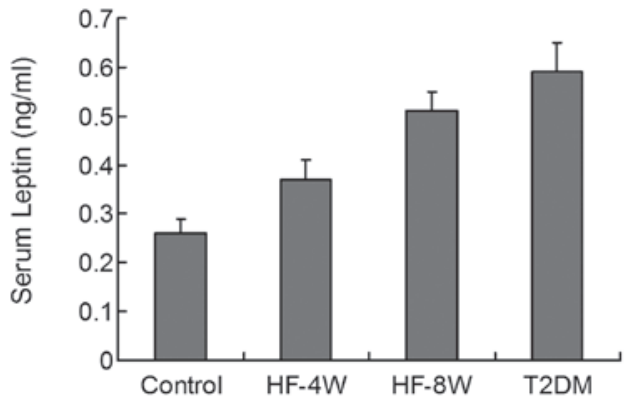

Figure 4. During the development of T2DM, the circulating concentrations of leptin gradually, yet significantly increased in the HF-4W, HF-8W and T2DM group rats $(\mathrm{P}<0.01)$. T2DM, type 2 diabetes mellitus.

\section{Discussion}

The T2DM rat model in our research closely mimics human T2DM. For the study of disease pathogenesis, prevention and treatment, an effective T2DM model is essential. However, the basic pathogenesis of the majority of T2DM models does not correspond with what occurs in human T2DM. For instance, obesity and IR in the db/db mouse and Zucker Diabetic Fatty (ZDF) rat result from monogenic mutations that are rare in humans $(16,17)$. In the present study, we induced T2DM by injecting low-dose STZ into HF-diet rats (HF feeding induced insulin resistance and low-dose STZ injection led to hyperglycaemia). The HF-diet rat is a useful model for human obesity and IR (18), which represents the interaction of nature and nurture; whereas STZ is a diabetogenic agent, which causes selective destruction of pancreatic $\beta$-cells. Injection of lowdose STZ into HF-diet rats yielded an experimental model of T2DM that replicates the natural history and metabolic characteristics of the human syndrome.

A number of previous studies (19-21) have indicated that low ghrelin levels are associated with IR, obesity and T2DM; however, the systematic investigation of ghrelin expression in the course of rat T2DM development has not been well docu- mented. The data presented in this study show that i) prior to the injection of STZ (comparison of control to HF-8W group), with the gain of body weight and aggravation of IR, the ghrelin levels decreased significantly; ii) following the STZ injection, no significant differences in ghrelin levels were found between the HF-8W and T2DM group rats; iii) the ghrelin production in the stomach and the GHS-R1a expression in the hypothalamus had the same tendency to change as circulating ghrelin levels.

Ghrelin is currently considered the most potent endogenous orexigenic peptide and plays a significant role in glucose homeostasis (4,22-24). A number of studies have shown that ghrelin decreases insulin sensitivity and has diabetogenic effects: the deletion of the genes encoding ghrelin and/or its receptor prevents a HF diet from inducing obesity $(25,26)$. Therefore, the reduction in ghrelin expression is capable of decreasing food intake, preventing a further increase in body weight, improving peripheral insulin sensitivity, and counteracting diabetes and obesity. Above all, we suggest that the decrease in ghrelin levels may be a compensatory mechanism for obesity and T2DM.

Since T2DM is commonly associated with obesity in humans, it is difficult to distinguish whether low ghrelin levels correlate with diabetes alone or occur in conjunction with obesity. Our results show for the first time that low ghrelin levels are associated with obesity rather than diabetes, since with the onset of T2DM, the ghrelin level no longer decreased. A possible explanation for this is that as insulin is able to suppress circulating ghrelin concentrations (27-29), with the onset of T2DM, cells were impaired and insulin production decreased and the suppression of ghrelin was reduced accordingly.

As previous studies have reported, ghrelin and leptin are involved in the regulation of GHS-R1a in the ARC, the former upregulating and the latter downregulating gene expression of GHS-R1a (30). In rats fed a HF-diet, low levels of ghrelin and high levels of leptin contribute to the reduction of GHS-R1a expression, whereas in T2DM rats, a small reduction in ghrelin levels leads to no additional reduction in GHS-R1a expression.
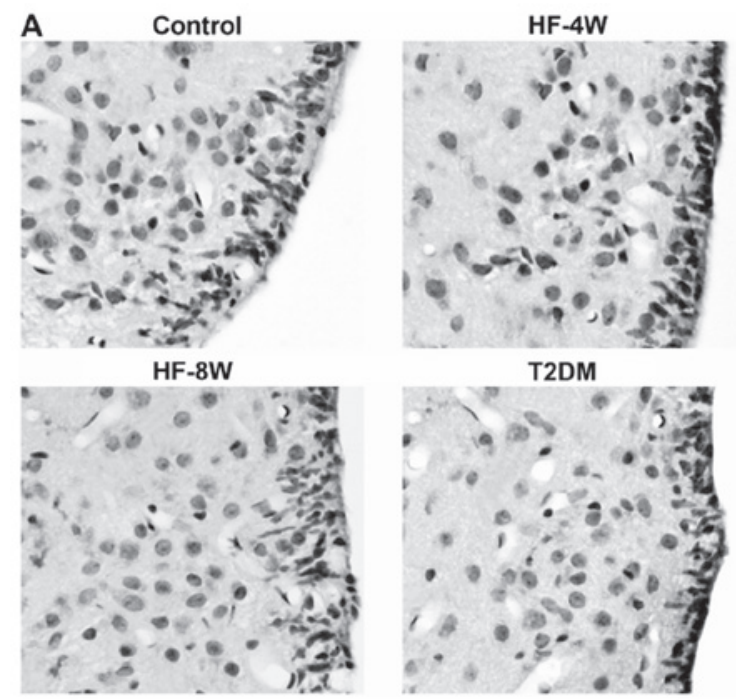

B

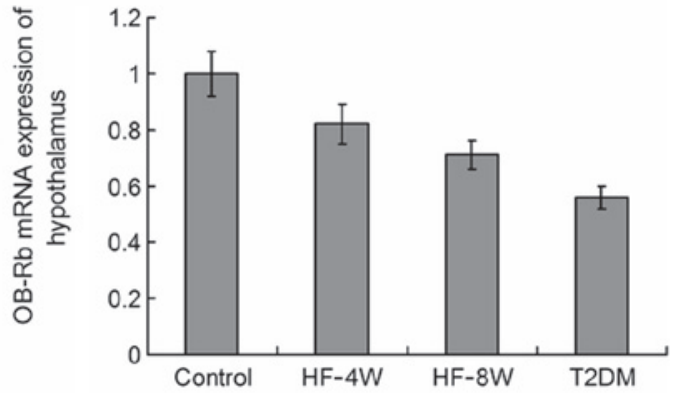

Figure 5. (A) The number of OB-Rb-expressing cells in the ARC was reduced when comparing T2DM to the control group rats (P<0.01). Magnification, $\mathrm{x} 400$. (B) The expression of OB-Rb mRNA showed similar results. ARC, arcuate nucleus; T2DM, type 2 diabetes mellitus. 
The mechanism by which ghrelin and leptin regulate GHS-R1a expression in the ARC remains unclear.

As numerous studies have demonstrated $(31,32)$, our study indicated that during the development of T2DM, with the increase in rat body weight, serum leptin concentrations and adipocyte leptin production were elevated significantly and were found to be associated with the downregulation of the hypothalamic leptin receptor.

The adipocyte-derived hormone leptin decreases food intake and increases energy expenditure to maintain normal body weight. The failure of elevated leptin levels to mediate weight loss defines a state known as leptin resistance (33). The diminished leptin receptors that lead to diminished physiological responses and defects in leptin action in the ARC may play a role in the pathogenesis of leptin-resistant obesity and T2DM.

Our data showed that ghrelin concentrations negatively correlated with insulin levels and IR, whereas serum leptin positively correlated with them. These data lend support to the theory that leptin and ghrelin may play significant roles in the development of hyperinsulinemia and insulin resistance. A negative correlation between fasting plasma ghrelin levels and serum leptin during the development of T2DM was also shown in our study, supporting the opposing effects of ghrelin and leptin on metabolic syndrome.

In conclusion, to the best of our knowledge, this is the first study to systematically investigate both ghrelin and leptin expression in the development of T2DM in the rat and to discover the fact that low ghrelin levels are associated with obesity rather than diabetes. However, further studies regarding the effect of ghrelin on glucose homeostasis and the development of T2DM should be conducted.

\section{Acknowledgements}

This study was supported by a grant from the Major Medical Research Program of Hebei Health Department in the People's Republic of China (07067).

\section{References}

1. Yang W, Lu J, Weng J, et al: Prevalence of diabetes among men and women in China. N Engl J Med 362: 1090-1101, 2010.

2. Mbanya JC, Motala AA and Sobngwi E: Diabetes in sub-Saharan Africa. Lancet 375: 2254-2266, 2010.

3. Jermendy G, Nadas J, Szigethy E, et al: Prevalence rate of diabetes mellitus and impaired fasting glycemia in Hungary: cross-sectional study on nationally representative sample of people aged 20-69 years. Croat Med J 51: 151-156, 2010.

4. Dieguez C, da Boit K, Novelle MG, et al: New insights in ghrelin orexigenic effect. Front Horm Res 38: 196-205, 2010.

5. De Vriese C, Perret J and Delporte C: Focus on the short- and long-term effects of ghrelin on energy homeostasis. Nutrition 26 : 579-584, 2010.

6. Zhang Y, Proenca R, Maffei M, Barone M, Leopold L and Friedman JM: Positional cloning of the mouse obese gene and its human homologue. Nature 372: 425-432, 1994.

7. Farooqi IS and O'Rahilly S: Leptin: a pivotal regulator of human energy homeostasis. Am J Clin Nutr 89: S980-S984, 2009.

8. Coppari R, Ichinose M, Lee CE, et al: The hypothalamic arcuate nucleus: a key site for mediating leptin's effects on glucose homeostasis and locomotor activity. Cell Metab 1: 63-72, 2005.

9. Cowley MA, Smith RG, Diano S, et al: The distribution and mechanism of action of ghrelin in the CNS demonstrates a novel hypothalamic circuit regulating energy homeostasis. Neuron 37: 649-661, 2003
10. Klok MD, Jakobsdottir S and Drent ML: The role of leptin and ghrelin in the regulation of food intake and body weight in humans: a review. Obes Rev 8: 21-34, 2007.

11. Klok K, Sone H and Yada T: Ghrelin is a physiological regulator of insulin release in pancreatic islets and glucose homeostasis. Pharmacol Ther 118: 239-249, 2008.

12. Reed MJ, Meszaros K, Entes LJ, et al: A new rat model of type 2 diabetes: the fat-fed, streptozotocin-treated rat. Metabolism 49: 1390-1394, 2000

13. Zhang F, Ye C, Li G, et al: The rat model of type 2 diabetic mellitus and its glycometabolism characters. Exp Anim 52: 401-407, 2003.

14. Srinivasan K, Viswanad B, Asrat L, Kaul CL and Ramarao P. Combination of high-fat diet-fed and low-dose streptozotocintreated rat: a model for type 2 diabetes and pharmacological screening. Pharmacol Res 52: 313-320, 2005.

15. Islam MS and Choi H: Nongenetic model of type 2 diabetes: a comparative study. Pharmacology 79: 243-249, 2007.

16. Peterson RG, Shaw WN and Neel MA: Zucker diabetic fatty rat as a model for non-insulin-dependent diabetes mellitus. ILAR News 32: 16-19, 1990.

17. Chang AY: Spontaneous diabetes in animals. Gen Pharmacol 9: 447-450, 1978.

18. Woods SC, Seeley RJ, Rushing PA, D'Alessio D and Tso P: A controlled high-fat diet induces an obese syndrome in rats. J Nutr 133: 1081-1087, 2003.

19. Ukkola O, Poykko S, Paivansalo M and Kesäniemi YA: Interactions between ghrelin, leptin and IGF-I affect metabolic syndrome and early atherosclerosis. Ann Med 40: 465-473, 2008.

20. Pacifico L, Poggiogalle E, Costantino F, et al: Acylated and nonacylated ghrelin levels and their associations with insulin resistance in obese and normal weight children with metabolic syndrome. Eur J Endocrinol 161: 861-870, 2009.

21. Serra-Prat M, Alfaro SR, Palomera E, et al: Relationship between ghrelin and the metabolic syndrome in the elderly: a longitudinal population-based study. Clin Endocrinol (Oxf) 70: 227-232, 2009.

22. Sun Y, Asnicar M and Smith RG: Central and peripheral roles of ghrelin on glucose homeostasis. Neuroendocrinology 86: 215-228, 2007.

23. Yada T, Dezaki K, Sone H, et al: Ghrelin regulates insulin release and glycemia: physiological role and therapeutic potential. Curr Diabetes Rev 4: 18-23, 2008.

24. Dezaki K, Kakei M and Yada T: Ghrelin uses Galphai2 and activates voltage-dependent $\mathrm{K}^{+}$channels to attenuate glucoseinduced $\mathrm{Ca}^{2+}$ signaling and insulin release in islet beta-cells: novel signal transduction of ghrelin. Diabetes 56: 2319-2327, 2007.

25. Wortley KE, del Rincon JP, Murray JD, et al: Absence of ghrelin protects against early-onset obesity. J Clin Invest 115: 3573-2578, 2005.

26. Zigman JM, Nakano Y, Coppari R, et al: Mice lacking ghrelin receptors resist the development of diet-induced obesity. J Clin Invest 115: 3564-3572, 2005.

27. Flanagan DE, Evans ML, Monsod TP, et al: The influence of insulin on circulating ghrelin. Am J Physiol Endocrinol Metab 284: E313-E316, 2003.

28. Ueno M, Carvalheira JB, Oliveira RL, Velloso LA and Saad MJ: Circulating ghrelin concentrations are lowered by intracerebroventricular insulin. Diabetologia 49: 2449-2452, 2006.

29. Fick LJ, Cai F and Belsham DD: Hypothalamic preproghrelin gene expression is repressed by insulin via both PI3-K/Akt and ERK1/2 MAPK pathways in immortalized, hypothalamic neurons. Neuroendocrinology 89: 267-275, 2009.

30. Nogueiras R, Tovar S, Mitchell SE, et al: Regulation of growth hormone secretagogue receptor gene expression in the arcuate nuclei of the rat by leptin and ghrelin. Diabetes 53: 2552-2558, 2004.

31. Al-Shoumer KA, Al-Asousi AA, Doi SA and Vasanthy BA: Serum leptin and its relationship with metabolic variables in Arabs with type 2 diabetes mellitus. Ann Saudi Med 28: 367-370, 2008.

32. Levin BE, Dunn-Meynell AA, Ricci MR and Cummings DE: Abnormalities of leptin and ghrelin regulation in obesity-prone juvenile rats. Am J Physiol Endocrinol Metab 285: E949-E957, 2003.

33. Myers MG, Cowley MA and Munzberg H: Mechanisms of leptin action and leptin resistance. Annu Rev Physiol 70: 537-556, 2008 